\title{
Surface morphologic evaluation of orthodontic bonding systems under conditions of cariogenic challenge
}

\author{
Erika Machado CALDEIRA(a) \\ Vicente TELLES(b) iD \\ Claudia Trindade MATTOS(a) \\ Matilde da Cunha Gonçalves \\ NOJIMA(c) iD \\ (a) Universidade Federal Fluminense - UFF, \\ School of Dentistry, Department of \\ Orthodontics, Niterói, RJ, Brazil. \\ (b) University of Pittsburgh, School of Dental \\ Medicine, Department of Oral Biology, \\ Pittsburgh, PA, USA. \\ (c) Universidade Federal do Rio de Janeiro - \\ UFRJ, School of Dentistry, Department of \\ Orthodontics and Pediatric Dentistry, Rio de \\ Janeiro, RJ, Brazil
}

Declaration of Interests: The authors certify that they have no commercial or associative interest that represents a conflict of interest in connection with the manuscript.

\section{Corresponding Author:}

Matilde da Cunha Gonçalves Nojima

E-mail: matildenojima@uol.com.br

https://doi.org/10.1590/1807-3107bor-2019.vol33.0029

Submitted: June 6, 2018

Accepted for publication: February 26, 2019

Last revision: March 8, 2019

\begin{abstract}
Orthodontic bonding systems are submitted to demineralization and remineralization dynamics that might compromise their surface smoothness, and favor biofilm aggregation and caries development. The aim of the present study was to evaluate the effects of a cariogenic challenge model (in vitro $\mathrm{pH}$-cycling model) on the surface roughness and topography of 3 bonding materials: Transbond ${ }^{\mathrm{TM}} \mathrm{XT}(\mathrm{XT})$, Transbond ${ }^{\mathrm{TM}}$ Plus Color Change (PLUS) and Fuji Ortho ${ }^{\mathrm{TM}}$ LC (FUJI), by means of Atomic Force Microscopy (AFM). Six specimens with standardized dimensions and surface smoothness were fabricated per group, and the materials were manipulated in accordance with the manufacturers' instructions. No polishing was necessary. AFM tests were performed before and after $\mathrm{pH}$-cycling, taking 3 readouts per specimen. The roughness results ( $\mathrm{Ra})$ were obtained at nanometric levels $(\mathrm{nm})$ and surface records were acquired in two- and three-dimensional images of height and lock-in phase of the material components. The surfaces of all groups analyzed in the study were morphologically altered, presenting images suggestive of matrix degradation and loss of matrix-load integrity. FUJI presented the greatest increase in surface roughness, followed by XT and PLUS, respectively $(p \leq 0.001)$. Nevertheless, the roughness values found did not present sufficient degradation to harbor bacteria. The surface roughness of all tested materials was increased by $\mathrm{pH}$-cycling. The use of materials capable of resisting degradation in the oral environment is recommended, in order to conserve their integrity and of the surrounding tissues.
\end{abstract}

Keywords: Microscopy, Atomic Force; Dental Materials; Orthodontics; Tooth Demineralization; Surface Properties.

\section{Introduction}

The introduction of bonding materials into Orthodontics, such as composites and resin-modified glass ionomer cements, has allowed the specialty to become more esthetic and conservative, with emphasis on simplification of clinical procedures. However, placement of orthodontic appliances leads to an increase in the number of retentive surfaces for biofilm accumulation. ${ }^{1}$ As a result, studies reporting the appearance of cavity lesions during orthodontic treatment, especially in the vestibular surface in proximity to brackets, can be found in literature. ${ }^{2,3,4}$ Other 
studies point out that bonding materials' properties, such as surface roughness and fluoride release, can influence risk of development of caries. 5,6,7,8,9,10,11

An ideal orthodontic bonding material, besides being able to resist unintentional debonding forces, must be biocompatible and maintain its biological, physical and chemical properties under any condition. Due to the complexity of the oral cavity, they must be capable of withstanding salivary biochemistry, constant changes in $\mathrm{pH}$, different temperatures, and particularly the resident oral microbiota. ${ }^{12,13}$ However, no material is ideal, and degradation happens under stress related to increased bacterial activity and decreased salivary $\mathrm{pH}$.

Material degradation results in surface roughness, which has a significant impact on esthetic appearance and discoloration, as well as plaque accumulation, and consequently, on the development of secondary caries and gingival irritation. ${ }^{14,15}$ Areas of microroughness may also lead to the fracture of fragile materials. ${ }^{14}$ At the same time, smooth surfaces assure greater comfort to the patient and facility in performing oral hygiene. The quality of a dental material surface is directly related to its brightness, roughness, color, polarity and morphology. ${ }^{14}$ Nevertheless, there is a lack of literature regarding orthodontic bonding materials' degradation under cariogenic challenge. ${ }^{16,17,18}$

Given the above, this study aims to evaluate the effects of simulated conditions of in vitro cariogenic challenges on the surface roughness and topography of three orthodontic bonding materials. We hypothesize that their degradation differs under cariogenic challenges. If confirmed, this knowledge can be applied to clinical practice when choosing a bonding system for patients with higher caries risk.

To test this hypothesis, $\mathrm{pH}$-cycling and Atomic Force Microscopy (AFM) were performed. $\mathrm{pH}$-cycling has frequently been applied in research due to its capacity for in vitro reproduction of the intraoral dynamics of demineralization and remineralization. ${ }^{19}$ Atomic Force Microscopy (AFM) has been extensively used in studies with dental materials for its capability to capture two-dimensional images, in addition to three-dimensional topographic and surface roughness details with nanometric resolution. ${ }^{14,20}$

\section{Methodology}

\section{Orthodontic bonding systems selection}

Three orthodontic bonding systems widely used in clinical practice and research were selected due to their different compositions and properties (Table 1). Transbond ${ }^{\mathrm{TM}} \mathrm{XT}$ Light Cure Adhesive is a light cure bonding composite, Transbond ${ }^{\mathrm{TM}}$ PLUS Color Change is a fluoride-releasing color-changing light cure bonding composite, and Fuji Ortho ${ }^{\mathrm{TM}} \mathrm{LC}$ is a resinmodified glass ionomer cement. The materials were stored at room temperature until use.

\section{Pilot study and sample size calculation}

Following each step of the methodology, a pilot study with 3 specimens was conducted to confirm their feasibility for an AFM analysis. With the standard deviation of 4.16 obtained from this pilot study, a sample size calculation was performed based on a $7 \mathrm{~nm}$ observable difference, an $\alpha=0.05$, and a $\beta=0.2$. This indicated the need for six specimens in each group (XT, PLUS and FUJI), adding to a total of 18 specimens.

\section{Preparation of specimens}

To standardize the dimensions of the specimens, a prefabricated Teflon matrix with perforations of $5 \mathrm{~mm}$ of diameter and $2 \mathrm{~mm}$ of thickness was used, as described in a previous study. ${ }^{7}$ A single researcher manipulated the materials in accordance with the manufacturers' instructions, and then inserted them into the matrix in a single increment. Both light cure bonding composites (XT and PLUS) were inserted into the matrix directly from their syringe. The resin-modified glass ionomer cement (FUJI) was manipulated and inserted into the matrix with the plastic spatula provided by the manufacturer. With the aid of two thin glass slides (1 mm each) and polyester strips of $0.05 \mathrm{~mm}$ (FAVA Ind. Com. São Paulo, SP, Brazil), specimens with smooth surfaces were produced. This technique to smooth and flatten the surface reduces the incorporation of air bubbles into the body of the material. $715,21,22,23,24,25$ Light curing was performed for 40 seconds on each surface, using halogen light (Foto Optilight LD Max, Gnatus - 50/60 Hz), with 
Table 1. Orthodontic bonding systems' composition, manufacturer and sample distribution.

\begin{tabular}{|c|c|c|}
\hline Materials (Group) & Composition & Manufacturers and batch \\
\hline \multirow{5}{*}{$\begin{array}{l}\text { Transbond }{ }^{T M} \mathrm{XT} \text { light cure } \\
\text { adhesive (group XT) }\end{array}$} & Bisphenol A diglycidyl ether dimethacrylate (BisGMA) & 3M Unitek (Monrovia, USA) \\
\hline & Bisphenol A bis(2-hydroxyethyl ether) dimethacrylate & N159231 \\
\hline & Diphenyliodonium hexafluorophosphate & \\
\hline & Silane treated silica & \\
\hline & Silane treated quartz & \\
\hline \multirow{7}{*}{$\begin{array}{l}\text { Transbond }{ }^{T M} \text { PLUS color } \\
\text { change adhesive (group } \\
\text { plus) }\end{array}$} & Bisphenol A diglycidyl ether dimethacrylate (BisGMA) & 3M Unitek (Monrovia, USA) \\
\hline & Glass reacted with hydrolized silane & N172805 \\
\hline & Polyethylene glycol dimethacrylate & \\
\hline & Citric acid dimethacrylate oligomer & \\
\hline & Silane treated silica & \\
\hline & Silane treated quartz & \\
\hline & 2,6-di-tert-butyl-p-cresol (BHT) & \\
\hline \multirow{6}{*}{$\begin{array}{l}\text { Fuji Ortho }{ }^{\text {TM }} \text { LC (group } \\
\text { FUJI) }\end{array}$} & Alumino-silicate glass & GC America Corporation (Tokyo, Japan) \\
\hline & Polyacrylic acid & 902121 \\
\hline & 2-Hydroxyethyl methacrylate (HEMA) & \\
\hline & $2,2,4$, Trimethyl hexamethylene dicarbonate & \\
\hline & Triethylene glycol dimethacrylate (TEGDMA) & \\
\hline & Proprietary Ingredient & \\
\hline
\end{tabular}

the active tip of the equipment directly touching the glass slides. ${ }^{719,26}$

Specimens were removed from the matrix after a 10 minute mean time. ${ }^{27}$ Then, they were stored in a humidifier for 24 hours to await the maturation process recommended for glass ionomer cements, and to avoid syneresis and imbibition. This storage condition was maintained until the beginning of the experimental stage. ${ }^{19,28}$

To perform the AFM test, the specimens were attached with sticky wax (Newwax, Technew, Rio de Janeiro, RJ, Brazil) to glass devices, maintaining the surface of interest parallel to the device.

\section{Atomic force microscopy - initial assessment}

Initial surface roughness ( $\mathrm{Ra}$ ) and topography analyses were performed before submission to $\mathrm{pH}$-cycling. In the delimited center of each specimen, three distinct readouts were taken, obtained by an atomic force microscope (AFM; JPK Nanowizard, Nr: H-01-0086), with a noncontact tip coated with silicon (NCLR-20; NanoWorld, Neuchâtel, Switzerland), with a constant force of $48 \mathrm{~N} / \mathrm{mm}$ and resonance frequency of $190 \mathrm{kHz}$. The specimen surfaces were kept stable by means of constant oscillation amplitude. Fields of vision of $20 \mu \mathrm{m} \times 20 \mu \mathrm{m}$ of digitization were considered and saved using a slow scan rate $(0.8 \mathrm{~Hz}) .^{29}$

The images were processed by a single operator using a specific program (JPK Image Processing software, version 3.0; JPK Instruments AG, Berlin, Germany). For each readout, the numerical roughness value ( $\mathrm{nm}$ ) of the surface, its two-dimensional record, and its three-dimensional topography were obtained. The vertical changes correspond to the different regions, these being light and dark according to the height recorded.

\section{pH-cycling}

The demineralizing solution was prepared with $0.05 \mathrm{M}$ of acetate buffer ( $\mathrm{pH} 5.0$ ), $1.28 \mathrm{mmol} / \mathrm{L} \mathrm{Ca}$; $0.74 \mathrm{mmol} / \mathrm{L} \mathrm{P}$ and $0.03 \mu \mathrm{g} / \mathrm{mL}$ F. The remineralizing solution ( $\mathrm{pH} 7.0$ ) contained $1.5 \mathrm{mmol} / \mathrm{L} \mathrm{Ca}$; $0.9 \mathrm{mmol} / \mathrm{L} \mathrm{P} ; 150 \mathrm{mmol} / \mathrm{L} \mathrm{KCl}$ and $0.05 \mu \mathrm{g} / \mathrm{mL} \mathrm{F}$ in $0.1 \mathrm{~mol} / \mathrm{L}$ of Tris buffer. ${ }^{30}$

Similarly to Queiroz, ${ }^{30}$ in each cycle the proportion of solution per area of specimen was maintained at a volume of $6.25 \mathrm{~mL} / \mathrm{mm}^{2}$ of demineralizing saliva 
and $3.12 \mathrm{~mL} / \mathrm{mm}^{2}$ of remineralizing saliva. To do this, only the surfaces of specimens remained exposed. The other areas remained sealed with sticky wax throughout the entire cycle.

During the nine days of cycling, the 18 specimens were kept in a microbiological oven at $37^{\circ} \mathrm{C}$, separated in receptacles named according to the 3 groups of materials.

The cycle of salivary changes lasted for eight days. The daily cycle dynamics consisted of keeping the specimens for 4 hours in the demineralizing solution, after which they were removed and washed with deionized water, and then immersed in the remineralizing solution for 20 hours. At the end of the fourth day, the solutions were changed to avoid saturation. On the ninth day, the specimens remained only in the remineralizing solution for 24 hours, finishing the cycling period..$^{30}$

\section{Atomic force microscopy - final assessment}

After the simulated cariogenic challenge, the specimens proceeded to the final AFM analyses to obtain the roughness ( $\mathrm{Ra}$ ) and surface topography records by performing three distinct readouts in the delimited center of each specimen, under similar conditions to those in the initial analysis.

\section{Statistical analysis}

The data from the surface roughness analysis were submitted to statistical analysis in the SPSS 17.0 software (Statistical Package for Social Sciences, SPSS Inc., Chicago, III). Normality of data was tested and confirmed with the Shapiro-Wilk test. The paired $t$-test was used to compare surface roughness before and after $\mathrm{pH}$-cycling of each material, while the differences between these were verified by the analysis of variance (ANOVA) and Tukey's test. The difference between means was considered significant when values of $p<0.05$ were obtained. The topography and surface images obtained were descriptively analyzed.

\section{Results}

The initial surface roughness evaluation revealed that there was no statistically significant difference between Groups XT and PLUS ( $p>0.05$ ), with FUJI presenting the highest roughness values, as expressed in Table $2(\mathrm{p}<0.05)$. For the final roughness data, statistically significant differences were found among all the groups, with PLUS presenting a lower final roughness value than XT $(\mathrm{p}<0.05)$ and FUJI demonstrating the highest roughness value after submission to the cariogenic challenge $(p<0.05)$ (Table 2). The final roughness of the groups, in decreasing order, was presented as follows: FUJI $>$ XT $>$ PLUS. The paired t-test showed that all the groups presented a significant increase in surface roughness after $\mathrm{pH}$-cycling $(\mathrm{p} \leq 0.001)$.

Images of the surfaces of each material before and after exposure to the cariogenic challenge, by means of AFM, demonstrated that all the materials underwent significant surface alterations (Figures 1, 2, and 3).

Qualitative analysis by atomic force microscopy of Group XT showed initial images with good surface integrity and flat morphology. After the cariogenic challenge, the material underwent noticeable surface

Table 2. Surface roughness results $(\mathrm{Ra}-\mathrm{nm})$ derived from the images obtained of specimens before and after $\mathrm{pH}$-cycling, by means of AFM, according to the materials analyzed.

\begin{tabular}{lcccc}
\hline Groups & AFM & Mean roughness in Ra $-\mathrm{nm}(\mathrm{SD})$ & t-test & ANOVA* \\
\hline \multirow{2}{*}{ XT } & Initial & $11.74(2.91)$ & $\mathrm{p}=0.001$ & $\mathrm{~A}$ \\
& Final & $32.32(6.37)$ & & $\mathrm{C}$ \\
PLUS & Initial & $11.54(1.48)$ & $\mathrm{p} 0.001$ & $\mathrm{~A}$ \\
& Final & $21.53(2.29)$ & & $\mathrm{B}$ \\
FUJI & Initial & $21.24(4.62)$ & $\mathrm{p}=0.001$ & $\mathrm{~B}$ \\
& Final & $53.78(7.33)$ & $\mathrm{D}$ \\
\hline
\end{tabular}

*Different letters express statistically significant different values $(p<0.05)$. 

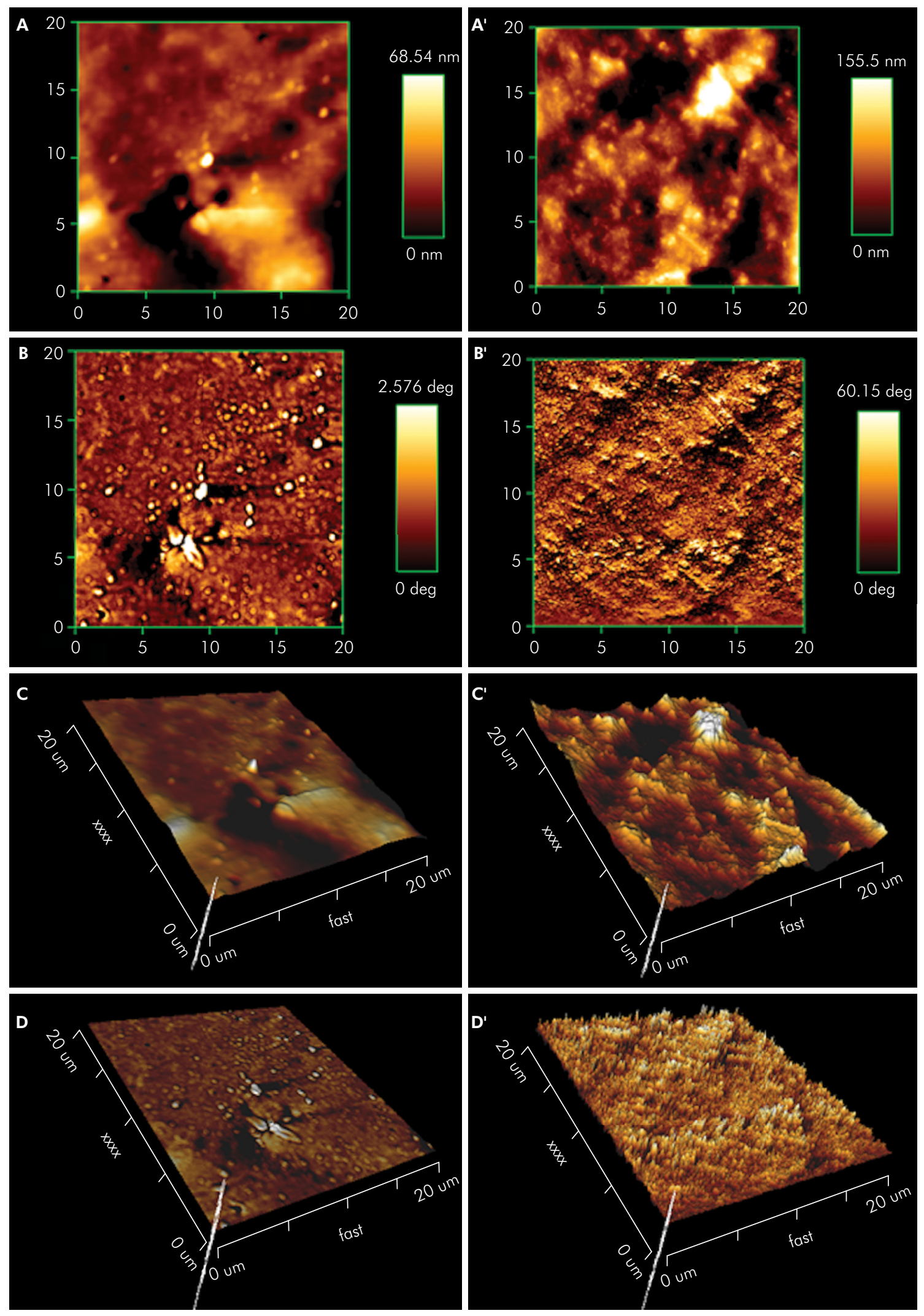

Figure 1. Photomicrographs in AFM of specimen surfaces from Group XT, before and after $\mathrm{pH}$-cycling, respectively being: $\mathrm{A}$ and $A^{\prime}$ - two-dimensional images in height; $B$ and $B^{\prime}$ - two-dimensional images of lock-in phase; $C$ and $C^{\prime}$ - three-dimensional images in height; $\mathrm{D}$ and $\mathrm{D}^{\prime}$ - three-dimensional images of lock-in phase. 

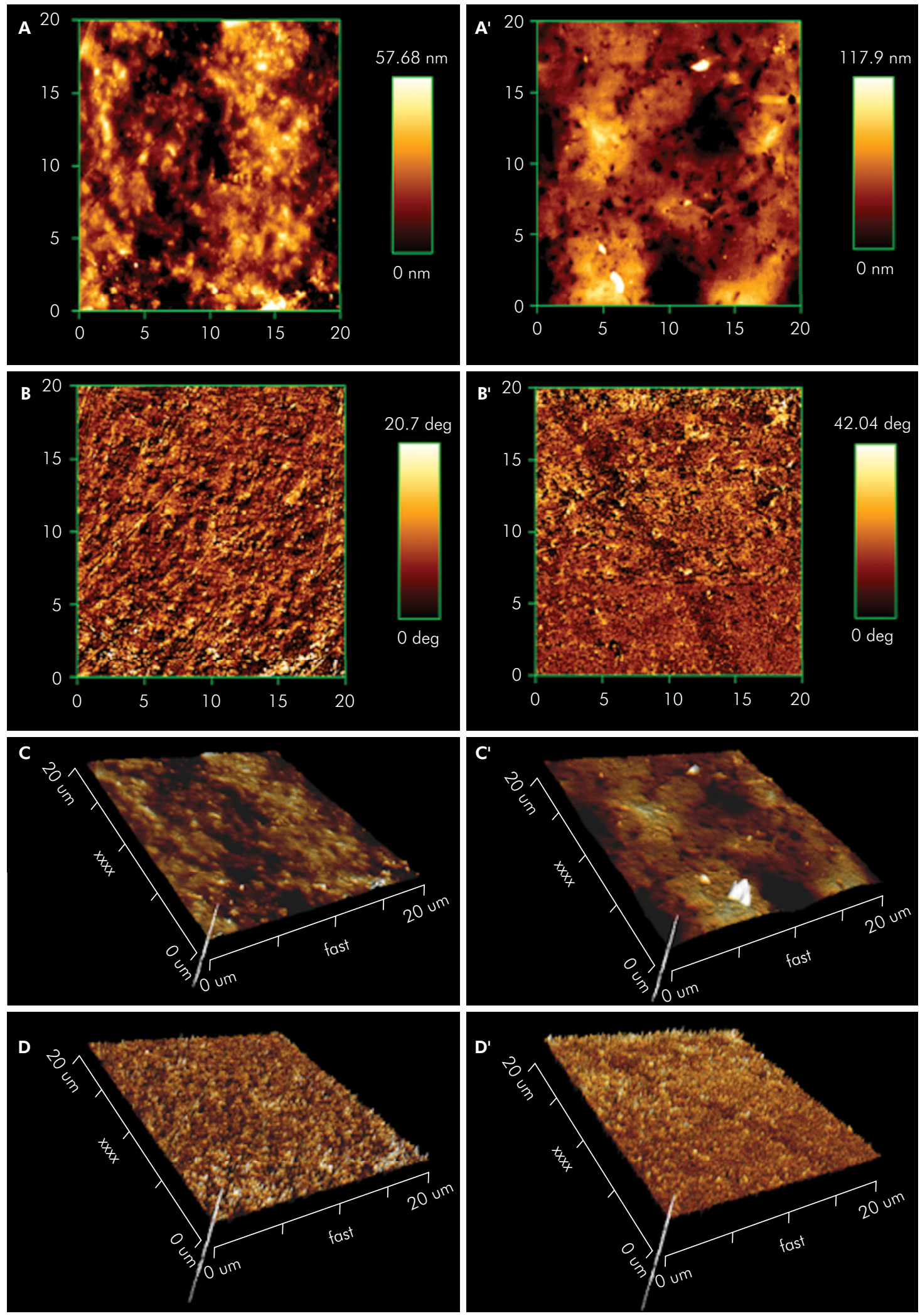

Figure 2. Photomicrographs in AFM of specimen surfaces from Group PLUS, before and after $\mathrm{pH}$-cycling, respectively being: $\mathrm{A}$ and $A^{\prime}$ : two-dimensional images in height; $B$ and $B^{\prime}$ : two-dimensional images of lock-in phase; $C$ and $C^{\prime}$ : three-dimensional images in height; $D$ and $D^{\prime}$ : three-dimensional images of lock-in phase. 

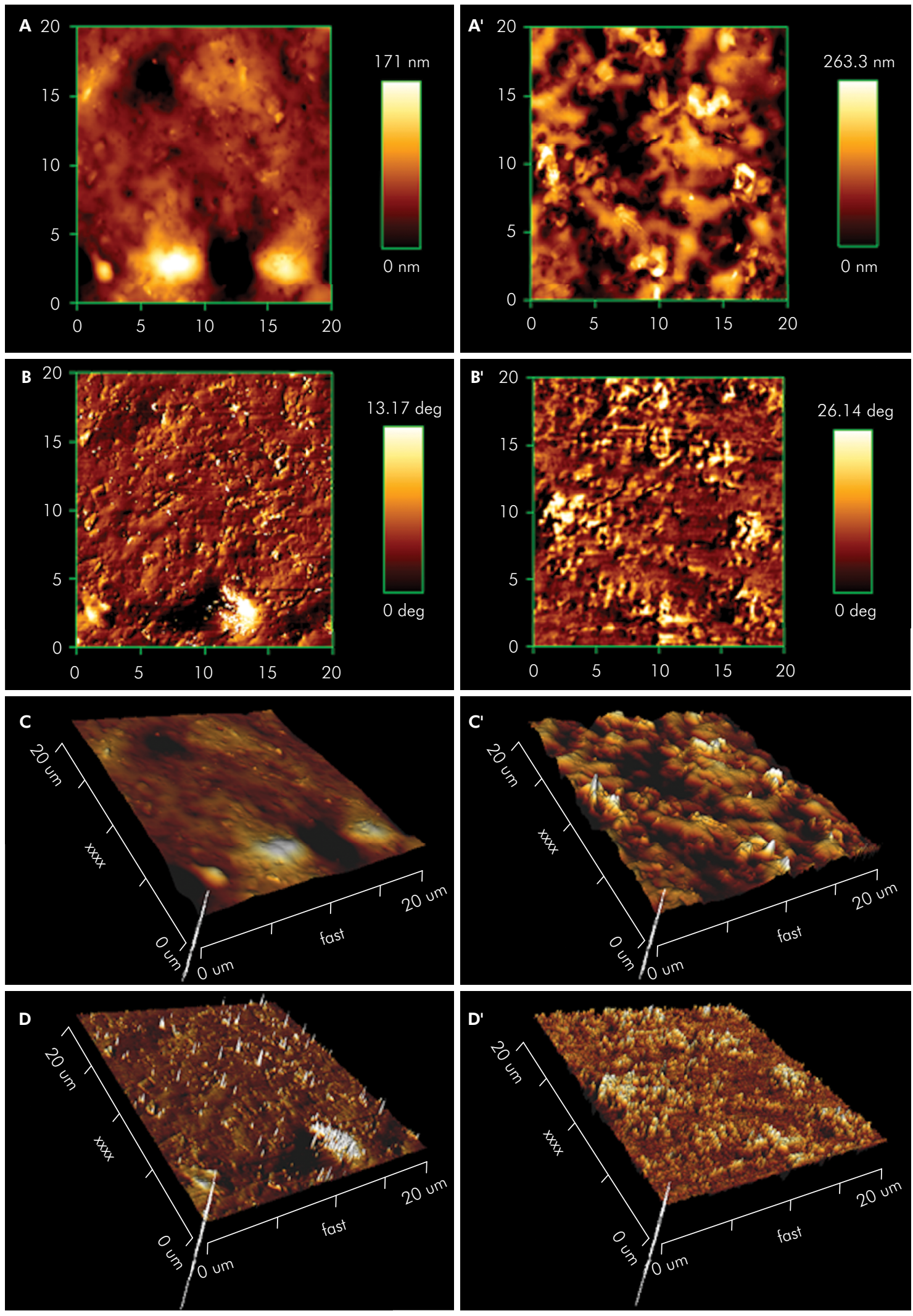

Figure 3. Photomicrographs in AFM of specimen surfaces from Group FUJl, before and after $\mathrm{pH}$-cycling, respectively being: $\mathrm{A}$ and $A^{\prime}$ : two-dimensional images in height; $B$ and $B^{\prime}$ : two-dimensional images of lock-in phase; $C$ and $C^{\prime}$ : three-dimensional images in height; $D$ and $D^{\prime}$ : three-dimensional images of lock-in phase. 
alteration, suggesting organic matrix destruction and protrusion of load particles (Figure 1).

As shown in Figure 2, Group PLUS initially presented a larger quantity of load particles than XT that were smaller in size and more uniformly distributed. However, its initial three-dimensional topographic morphology was similar to that of Group XT, both showing a perceptible pattern of smoothness at nanometric levels. The final images of Group PLUS revealed a more homogenous structure in comparison to the final images of XT and FUJI, with few areas of load particle protrusion and matrix deterioration. Nevertheless, darkened regions along the surface denote the increase in roughness, with images suggestive of load particle detachment.

Group FUJI revealed initial images similar to the final images of Group PLUS, in agreement with the data of the quantitative aspect (Figure 3). Therefore, this material was already rougher in the initial period before $\mathrm{pH}$-cycling. The images suggest more voluminous load particles and a more heterogeneous distribution, characterizing their greater roughness. After the simulated cariogenic challenge, Group FUJI presented the greatest structural changes, with its matrix being degraded throughout the surface, denoting loss of load particles and protrusion of the remaining glass particles, observed in microrelief forms.

\section{Discussion}

Surface roughness is directly related to the microrelief forms inherent to the material, or those caused by the treatment, and is of extreme clinical relevance, as rough surfaces tend to harbor bacteria, promote pigment absorption and increase surface deterioration. ${ }^{31,32}$

In the present study, to obtain samples with smooth surface, two glass slides and polyester strips were used, and no finishing and polishing were performed. According to Janus et al., ${ }^{15}$ there is an increase in surface roughness when abrasive papers are used, mainly due to abrasion of the resin matrix and load particles by heating. This results in detachment of the particles and their agglomerates during polishing. Therefore, this procedure is contraindicated when producing specimens to assess surface roughness.

Morphological evaluations represent the preliminary procedures for the study of biomaterial surface changes. Atomic Force Microscopy was the method of evaluation chosen due to its ability to distinguish surface roughness better than $2 \mathrm{D}$ profilometry, in addition to guaranteeing a more detailed definition of surface texture than scanning electron microscopy. ${ }^{14,20}$ Three-dimensional qualitative evaluation was used as a parameter because it has been shown to be more realistic than the profiles obtained in 2D, and is more representative than two-dimensional images. ${ }^{14}$ Another important peculiarity of AFM is the fact that it allows mapping of specimen surfaces in the absence of contact with them, which excludes damage that may be caused by the mechanical sensor of a rugosimeter. ${ }^{15}$ Due to its high resolution and ease of sample preparation, AFM is considered a superior research tool to quantitively measure the surface roughness of orthodontic materials. ${ }^{33}$

In 2007, Kakaboura ${ }^{14}$ conducted a study comparing various methodologies for evaluating the surface characteristics of composite resins. He pointed out that the results obtained by the AFM technique could not be explored, because no studies using a similar methodology were found in the literature. Although some time has passed, few data have been found in the field of orthodontic bonding materials to support this discussion. With knowledge of the exact size of load particles and their shape, it would be easier to conduct an approach to the results found in the present study. It is important to point out that the more regular and smaller the load particles of the material are, greater the chance of obtaining surface smoothness. ${ }^{14,34}$

Surface roughness values ( $\mathrm{Ra}$ ) lower than $1 \mu \mathrm{m}$ give the material a visually smooth appearance, ${ }^{14}$ due to its visible light wavelength. This is in agreement with the visual appearance of the specimens analyzed in this research which, even after the cariogenic challenge, maintained mirror-smooth surfaces. This favorable visual aspect does not imply the absence of roughness. From the microbiologic point of view, roughness of $0.2 \mu \mathrm{m}$ is described 
in the literature as the initial limit for bacterial accumulation. ${ }^{5}$ Ra values exceeding this limit, in addition to greater plaque accumulation, provide retention niches for bacteria, which act as shelters. ${ }^{6}$ For the roughness values found in the present study, even after $\mathrm{pH}$-cycling, all the results were shown to be far from the roughness limit of $0.2 \mu \mathrm{m}$, including Fuji Ortho ${ }^{\mathrm{TM}}$ LC $(0.053 \mu \mathrm{m})$, as observed in Table 2. Nevertheless, one should be attentive to the fact that the roughness levels of all the materials were altered after the cariogenic challenge.

The heterogeneous profile of resin materials is characterized by the nature of hard load particles bound together by the soft resin matrix. The larger the portion of the organic matrix, the greater the chances of obtaining a smooth surface. The inorganic part may have a negative influence on surface smoothness of the material, depending on the nature, shape, quantity and size of the load particles, which are generally irregularly-shaped. ${ }^{15,34}$ It is considered more damaging to the surface of the material when there is greater compromise of the resin matrix in comparison to alterations related to the load particles because, in addition to the loss of matrix itself, undue exposure of the load also occurs, increasing the surface roughness. ${ }^{14,15}$ This explains the behavior found among similar materials such as XT and PLUS, in which the former presents a larger quantity of organic matrix in its composition, while the latter has a larger quantity of load particles (Figures 1 and 2).

Among the tested materials, FUJI presented the greatest surface alteration. By nature, glass ionomer cements (GIC), even when resin-reinforced, react in a more sensitive manner to syneresis and imbibition, as well as to abrasion and erosion, than composites. The presence of hydrophilic functional groups makes GICs behave as a synthetic hydrogel, capable of absorbing a considerable quantity of water, causing deep dimensional alterations and unsatisfactory mechanical properties. ${ }^{7,35}$ Previous studies have considered HEMA/TEGDMA substances to be water soluble, cytotoxic, and easily biodegraded in the oral cavity. ${ }^{8,27,31}$ Additionally, the glass particles have characteristically irregular shapes. Particularly when they are voluminous, the ability to obtain adequate surface smoothness is compromised, which explains the behavior of the material even before $\mathrm{pH}$-cycling. Within the context of cariogenic challenge simulation, throughout the entire surface of FUJI, the presence of microrelief forms and areas of peaks and depressions explained matrix degradation and/or detachment of the silicate aluminum glass particles, in addition to increased extrusion of the remaining load (Figure 3 ). ${ }^{15}$

The proposed cariogenic model was capable of degrading the materials by hydrolization of the inorganic particles, causing harm to the composites' polymeric network and polyHEMA chain, modifying both the physical and chemical properties of these structures. . $10,11,26,36$ Thus, the increase in roughness is directly related to greater biofilm accumulation and the possibility of greater material degradation, particularly under clinical conditions in the oral environment. Due to the longevity of orthodontic treatments and for adequate material selection, it's important to know the chemical composition and morphological characteristics of the bonding materials used..$^{20}$ This material must be capable of maintaining its integrity under adverse conditions of the oral environment, while maintaining its properties.

It is important to point out that the main limitation of this in vitro study is that it cannot be entirely extrapolated to clinical practice. During clinical bonding procedure, the very removal of excess material already produces roughness levels that are visible to the naked eye. Therefore, the initial surface smoothness in this study is artificial and underestimates the possible effects of in vivo material degradation. Further split-mouth randomized clinical trials would be desirable to determine material degradation and its impact in patients' oral health.

\section{Conclusion}

It was concluded that Fuji Ortho ${ }^{\mathrm{TM}} \mathrm{LC}$ was the material that underwent the most alteration in surface roughness and topography, followed by "Transbond ${ }^{\mathrm{TM}}$ XT Light Cure Adhesive" and "Transbond ${ }^{\text {TM }}$ PLUS Color Change. Nevertheless, from the microbiologic point of view, all the materials analyzed in this study maintained surface roughness below the initial limit for bacterial accumulation. 
Surface morphologic evaluation of orthodontic bonding systems under conditions of cariogenic challenge

\section{References}

1. Oeiras VJ, Silva VA, Azevedo LA, Lobato VS, Normando D. Survival analysis of banding and bonding molar tubes in adult patients over a 12-month period: a split-mouth randomized clinical trial. Braz Oral Res. 2016 Dec;30(1):e136. https://doi.org/10.1590/1807-3107bor-2016.vol30.0136

2. Büyükyilmaz T, Øgaard B. Caries-preventive effects of fluoride-releasing materials. Adv Dent Res. 1995;9(4):377-83. https://doi.org/10.1177/08959374950090040601

3. Al Maaitah EF, Adeyemi AA, Higham SM, Pender N, Harrison JE. Factors affecting demineralization during orthodontic treatment: a posthoc analysis of RCT recruits. Am J Orthod Dentofacial Orthop. 2011 Feb;139(2):181-91. https://doi.org/10.1016/i.ajodo.2009.08.028

4. Tufekci E, Dixon JS, Gunsolley JC, Lindauer SJ. Prevalence of white spot lesions during orthodontic treatment with fixed appliances. Angle Orthod. 2011 Mar;81(2):206-10. https://doi.org/10.2319/051710-262.1

5. Bollen CM, Lambrechts P, Quirynen M. Comparison of surface roughness of oral hard materials to the threshold surface roughness for bacterial plaque retention: a review of the literature. Dent Mater. 1997 Jul;13(4):258-69. https://doi.org/10.1016/S0109-5641(97)80038-3

6. Beyth N, Bahir R, Matalon S, Domb AJ, Weiss El. Streptococcus mutans biofilm changes surface-topography of resin composites. Dent Mater. 2008 Jun;24(6):732-6. https://doi.org/10.1016/i.dental.2007.08.003

7. Caldeira EM, Osório A, Oberosler EL, Vaitsman DS, Alviano DS, Nojima MC. Antimicrobial and fluoride release capacity of orthodontic bonding materials. J Appl Oral Sci. 2013 Jul-Aug;21(4):327-34. https://doi.org/10.1590/1678-775720130010

8. Malkoc S, Corekci B, Ulker HE, Yalçin M, Sengün A. Cytotoxic effects of orthodontic composites. Angle Orthod. 2010 Jul;80(4):571-6. https://doi.org/10.2319/092809-537.1

9. Bourbia M, Ma D, Cvitkovitch DG, Santerre JP, Finer Y. Cariogenic bacteria degrade dental resin composites and adhesives. J Dent Res. 2013 Nov;92(11):989-94. https://doi.org/10.1177/0022034513504436

10. Caldeira EM, Fidalgo TK, Passalini P, Marquezan M, Maia LC, Nojima MC. Effect of fluoride on tooth erosion around orthodontic brackets. Braz Dent J. 2012;23(5):581-5. https://doi.org/10.1590/S0103-64402012000500019

11. Chung SH, Cho S, Kim K, Lim BS, Ahn SJ. Antimicrobial and physical characteristics of orthodontic primers containing antimicrobial agents. Angle Orthod. 2017 Mar;87(2):307-12. https://doi.org/10.2319/052516-416.1

12. Aliping-McKenzie M, Linden RW, Nicholson JW. The effect of Coca-Cola and fruit juices on the surface hardness of glass-ionomers and 'compomers'. J Oral Rehabil. 2004 Nov;31(11):1046-52. https://doi.org/10.1111/j.1365-2842.2004.01348.x

13. Valinoti AC, Neves BG, da Silva EM, Maia LC. Surface degradation of composite resins by acidic medicines and pH-cycling. J Appl Oral Sci. 2008 Jul-Aug;16(4):257-65. https://doi.org/10.1590/S1678-77572008000400006PMID:19089257

14. Kakaboura A, Fragouli M, Rahiotis C, Silikas N. Evaluation of surface characteristics of dental composites using profilometry, scanning electron, atomic force microscopy and gloss-meter. J Mater Sci Mater Med. 2007 Jan;18(1):155-63. https://doi.org/10.1007/s10856-006-0675-8

15. Janus J, Fauxpoint G, Arntz Y, Pelletier H, Etienne O. Surface roughness and morphology of three nanocomposites after two different polishing treatments by a multitechnique approach. Dent Mater. 2010 May;26(5):416-25. https://doi.org/10.1016/i.dental.2009.09.014

16. Sifakakis I, Eliades T. Adverse reactions to orthodontic materials. Aust Dent J. 2017 Mar;62 Suppl 1:20-8. https://doi.org/10.1111/adj.12473

17. de Almeida CM, da Rosa WL, Meereis CT, de Almeida SM, Ribeiro JS, da Silva AF, et al. Efficacy of antimicrobial agents incorporated in orthodontic bonding systems: a systematic review and meta-analysis. J Orthod. 2018 Jun;45(2):79-93. https://doi.org/10.1080/14653125.2018.1443872

18. Okada EM, Ribeiro LN, Stuani MB, Borsatto MC, Fidalgo TK, Paula-Silva FW, et al. Effects of chlorhexidine varnish on caries during orthodontic treatment: a systematic review and meta-analysis. Braz Oral Res. 2016 Nov;30(1):e115. https://doi.org/10.1590/1807-3107bor-2016.vol30.0115

19. Silva KG, Pedrini D, Delbem AC, Cannon M. Effect of $\mathrm{pH}$ variations in a cycling model on the properties of restorative materials. Oper Dent. 2007 Jul-Aug;32(4):328-35. https://doi.org/10.2341/06-89

20. Karan S, Toroglu MS. Porcelain refinishing with two different polishing systems after orthodontic debonding. Angle Orthod. 2008 Sep;78(5):947-53. https://doi.org/10.2319/081307-374.1

21. Ilday NO, Bayindir $Y Z$, Bayindir F, Gurpinar A. The effect of light curing units, curing time, and veneering materials on resin cement microhardness. J Dent Sci. 2013 Jun;8(2):141-6. https://doi.org/10.1016/i.jds.2012.09.014

22. Phaneuf M, Haimeur A, França R. Effect of anaerobic cure of self-etch adhesive on degree of conversion and shear bond strength. Clin Oral Investig. 2018 Oct;e-pub. https://doi.org/10.1007/s00784-018-2645-1 
23. Fonseca GS, Correia AM, Griza S, Villarroel M, Takeshita WM, Mendonça AA. [Effect of intensity of light sources and barriers in ceramic hardness of dual-cured cement ]. Rev Odontol UNESP. 2015 Jul-Aug;44(4):207-12. Portuguese. https://doi.org/10.1590/1807-2577.1083

24. Werlang JFG, Dalfovo RJ, Neiva IF, Obici AC. [Curing-light attenuation and depth of cure of composite resins]. Arq Odontol. 2013 Jan-Mar;49(1):12-8. Portuguese. https://doi.org/10.7308/aodontol/2013.49.1.02

25. Barcellos DC, Borges AB, Batista GR, Gonçalves SE, Pucci CR, Borges AL. [Evaluation of microhardness and compressive strength of different indirect composite resins]. Braz Dent Sci. 2011 Jul-Dec;14(3/4):32-7. Portuguese.

26. Montenegro RV, Ribeiro GL, França KP, Brasileiro CC, Cavalcanti AL, Carlo HL, et al. Effect of load particle and storage time on the surface microhardness of esthetic restorative composites. Braz Res Ped Dent Integr Clin. 2010 Sep-Dec;10(3):345-50. https://doi.org/10.4034/pboci.v10i3.1083

27. Cattani-Lorente MA, Dupuis V, Payan J, Moya F, Meyer JM. Effect of water on the physical properties of resin-modified glass ionomer cements. Dent Mater. 1999 Jan;15(1):71-8. https://doi.org/10.1016/S0109-5641(99)00016-0

28. Diaz-Arnold AM, Holmes DC, Wistrom DW, Swift EJ Jr. Short-term fluoride release/uptake of glass ionomer restoratives. Dent Mater. 1995 Mar;11(2):96-101. https://doi.org/10.1016/0109-5641(95)80041-7

29. Silva DL, Mattos CT, Simão RA, de Oliveira Ruellas AC. Coating stability and surface characteristics of esthetic orthodontic coated archwires. Angle Orthod. 2013 Nov;83(6):994-1001. https://doi.org/10.2319/111112-866.1

30. Queiroz CS, Hara AT, Paes Leme AF, Cury JA. pH-cycling models to evaluate the effect of low fluoride dentifrice on enamel de- and remineralization. Braz Dent J. 2008;19(1):21-7. https://doi.org/10.1590/S0103-64402008000100004

31. Hansel C, Leyhausen G, Mai UE, Geurtsen W. Effects of various resin composite (co)monomers and extracts on two caries-associated micro-organisms in vitro. J Dent Res. 1998 Jan;77(1):60-7. https://doi.org/10.1177/00220345980770010601

32. Teixeira EC, Thompson JL, Piascik JR, Thompson JY. In vitro toothbrush-dentifrice abrasion of two restorative composites. J Esthet Restor Dent. 2005;17(3):172-80. https://doi.org/10.1111/i.1708-8240.2005.tb00109.x

33. Choi S, Kim JH, Kim NJ, Lee SH, Kim H, Kim KA, et al. Morphological investigation of various orthodontic lingual bracket slots using scanning electron microscopy and atomic force microscopy. Microsc Res Tech. 2016 Dec;79(12):1193-9. https://doi.org/10.1002/jemt.22775

34. Conceição EN. Dentística: saúde e estética: materiais restauradores diretos. 2nd ed. Porto Alegre: Artmed; 2007.

35. Cefaly DF, Wang L, de Mello LL, dos Santos JL, dos Santos JR, Lauris JR. Water sorption of resin-modified glass-ionomer cements photoactivated with LED. Braz Oral Res. 2006 Oct-Dec;20(4):342-6. https://doi.org/10.1590/S1806-83242006000400011

36. Crisp S, Pringuer MA, Wardleworth D, Wilson AD. Reactions in glass ionomer cements: II. An infrared spectroscopic study. J Dent Res. 1974 Nov-Dec;53(6):1414-9. https://doi.org/10.1177/00220345740530062001 